\title{
ALIANÇA E AGENCIAMENTO ENTRE NATUREZA E SUBJETIVIDADE POR ERNST BLOCH E DELEUZE-GUATTARI
}

\section{ALLIANCE AND AGENCY BETWEEN NATURE AND SUBJECTIVITY BY ERNST BLOCH AND DELEUZE-GUATTARI}

\author{
Alan Rodrigo Padilha
}

\section{Instituto Federal do Paraná}

\section{RESUMO}

Este ensaio tem como temática dois conceitos filosóficos, a saber, o conceito de técnica da aliança de Ernst Bloch e o conceito de agenciamentos maquínico de Deleuze-Guattari, ambos desenvolvidos respectivamente em "O Princípio Esperança" de (1959) e, em "O Anti-Édipo" de (1972). Embora, tais conceitos pressuponham constelações distintas e, não designem uma univocidade de sentido, os mesmos, por outro lado, compõem vetores capazes de romper com a alienação da técnica sobre a natureza e de suas consequências enquanto produção capitalística. A técnica da aliança e os agenciamentos maquínicos apresentam processos sociais engajados em devires de coprodutividade, implicando em uma nova relação entre o humano e o não-humano, da técnica e da sociabilidade, da aliança homem-natureza como afirmação imanente de uma revolução criadora. Contrapondo-se a técnica burguesa e a axiomática do capitalismo universal. E tendo por referência a constituição de uma utopia concreta, por meio de uma técnica da aliança e por uma ecosofia a favor da vida, numa articulação ético-político, a nível dos três registros ecológicos, do meio ambiente, das relações sociais e da produção de subjetividade.

Palavras Chave: Aliança; Natureza; Capitalismo; Subjetividade.

\begin{abstract}
This essay has as its theme two philosophical concepts, namely, Ernst Bloch's concept of alliance technique and Deleuze-Guattari's concept of machinic assemblages, both developed respectively in "The Hope Principle" (1959) and in "The Anti-Oedipus" of (1972). Although such concepts presuppose distinct constellations and do not designate a univocity of meaning, they, on the other hand, comprise vectors capable of breaking with the alienation of technique from nature and its consequences as a capitalistic production. The alliance technique and the machinic assemblages present social processes engaged in becomings of co-productivity, implying a new relationship between the human and the non-human, of technique and sociability, of the man/nature alliance as an immanent affirmation of a creative revolution. Opposing the bourgeois technique and the axiomatics of universal capitalism. And having as reference the constitution of a concrete utopia, through a technique of alliance and an ecosophy in favor of life, in an ethical-political articulation, at the level of the three ecological registers, the environment, social relations and production of subjectivity.
\end{abstract}

KEYWORDS: Alliance; Nature; Capitalism; Subjectivity. 


\section{INTRODUÇÃO}

Os principais desafios da contemporaneidade estão ligados a questões ambientais, e de uma forma muito específica aos modos de produção social de subjetividade, isto é, envolve um campo problemático entre homem e natureza, em que somente uma postura ético-política poderá responder adequadamente ao problema. É preciso considerar a dinâmica de produção de bens e serviços como parte constituinte do processo de produção social de subjetividade, visto que desses fenômenos decorrem não somente os desequilíbrios ecológicos, mas os problemas sociais e econômicos que caminham para segmentaridade ${ }^{1}$ cada vez embrutecida e massificada pelo consumo midiático. Para Félix-Guattari (1990), tais problemas, se manifestam em três grandes registros ecológicos, a saber, as relações sociais, ambientais e o processo de produção de subjetividade. As três ecologias é um todo complexo do qual depende a vida no planeta. Neste sentido, cabe discutir o conceito de agenciamentos maquínicos e a técnica da aliança em Ernst Bloch, com objetivo de reinventar os modos de produção social de subjetividade, considerando o necessário enlace entre homem-natureza em seus componentes físico-químicos, orgânicos e antropomórficos em uma composição de homem, natureza e tecnologia.

Segundo Félix-Guattari (1990), o "Capitalismo Mundial Integrado" lança sobre os territórios existenciais semióticas de produção social de subjetividade formando blocos de estratificação e sobrecodificação que compõem os regimes econômicos, jurídicos, científicos, mas também de uma semiologia relativa aos equipamentos coletivos como a organização da cidade como semiótica arquitetônica e urbanística. O processo de formação de subjetividade está implicado por uma multiplicidade de agenciamentos em sistemas maquínicos, econômicos, sociais, tecnológicos e ecológicos, responsáveis pela produção de percepção, sensibilidade, afetos, desejos, valores e da produção de ideias, ora por aspirações emancipadoras, ora por pulsões retrógradas, conservadoras, e até mesmo fascista, de ordem nacionalista, étnica e religiosa (GUATTARI, 2006 p.12). Neste sentido, torna-se necessário, mobilizar uma micropolítica de transformação molecular frente aos processos de estratificação e ideologias segregativas como o nacionalismo, o fanatismo religioso, o racismo, a

\footnotetext{
${ }^{1}$ Conceito cunhado por Deleuze-Guattari que designa a micropolítica de segmentaridade molar e molecular que compreende os estratos sociais, ambientais e da própria formação de subjetividade.
} 
misoginia, a homofobia, a exploração do trabalho, a desvalorização da pessoa idosa e dos povos tradicionais.

No futuro a questão não será apenas a defesa da natureza, mas a de uma ofensiva para reparar o pulmão amazônico, para reflorescer o Saara. A criação de novas espécies vivas, vegetais e animais, está inelutavelmente em nosso horizonte e torna urgente não apenas adoção de uma ética ecosófica adaptada a essa situação, ao mesmo tempo terrificante e fascinante, mas também de uma política focalizada no destino da humanidade (GUATTARI,1990, p.53).

A ecosofia se caracteriza como um movimento ético, estético e político no sentido de uma filosofia do porvir, engajada em agenciamentos maquínicos com as questões ambientais, sociais e de produção de subjetividade. O pensamento ético em Deleuze e Guattari é uma experimentação que exige uma linha de fuga, um agenciamento maquínico de articulação ético-político nos três registros ecológicos, expressão de uma máquina de guerra contra a tecnocracia dos aparelhos de Estado que se revela pelo sistema de valor do capitalismo mundial integrado nivelando ao mesmo plano os bens materiais, culturais e ambientais por uma semiologia que capturou o conceito de ecossistema para área de inovação tecnológica e inversamente operacionalizou o conceito de sustentabilidade e responsabilidade ambiental para justificar tecnocraticamente o sistema de valor dos modos de produção capitalista.

Ernst Bloch é um pensador de tradição marxista, mas não menos crítico ao marxismo ortodoxo, este por sua vez, elabora uma tese aqui denominada de técnica da aliança envolvendo no limite as relações homem-natureza e consequentemente, todo modo de produção capitalista. Em o Princípio Esperança, Bloch faz a fundamentação daquilo que seria a base elementar de seu pensamento, passando a tratar do conceito de utopia, mas de uma utopia concreta segundo o qual se sustenta a partir dos sonhos diurnos.

Bloch é um materialista (cf. Lorenzoni, 2015), ou seja, ele parte das tendências e latências daquilo que se nos apresenta sem impor ideais externos à realidade. Isso, no entanto, de modo algum significa que ele sacrifica as dimensões subjetivas dos seres humanos diante daquilo que se nos apresenta: também essas dimensões pertencem ao seu conceito de natureza (cf. Bicca, 2013). Natureza não é sinônimo de matéria morta. Espírito e natureza deveriam ser concebidos como pertencentes a uma unidade originária (SCHÜTZ, 2021, p.211).

Bloch ao assumir o enlace entre natureza e subjetividade, também assume as condições na qual essa aliança se compõe, ou seja, pelos elementos materiais da própria natureza e pelas condições 
históricas e sociais, mas também dos pequenos sonhos diurnos e dos desejos humanos sempre na direção de uma utopia concreta.

O pensamento precisa se deixar surpreender e influenciar pelo devir do mundo mesmo para, dessa forma, na medida em que deixa conscientemente o novo surgir, alcançar uma esperança compreendida: "Docta spes, a 'esperança compreendida', torna claro assim o conceito de um princípio que não mais deixa o mundo" (Bloch, 2005, p.17). [...] O aqui e agora, tanto da sociedade quando da natureza, é, portanto, o ponto de partida. Nele já está contido o futuro como potência imanente. Utopia concreta, concebida enquanto esperança compreendida, só pode partir desse ponto: "Seu espaço é a possibilidade real e objetiva dentro do processo, na via do próprio objeto" (Bloch, 2005, p. 17). Em vez de ser deduzida desde algo impossível ou de uma terra de ninguém apenas imaginada, a utopia é conquistada justamente a partir da proximidade (SCHÜTZ, 2021, p.215).

O correspectivo de utopia e esperança é consciência crítica que mobiliza a concreção criadora da realidade, e neste caso, estabelece-se por uma via objetiva conectada com os modos de produção social de subjetividade em seu sentido mais complexo que envolve o registro de uma ecopolítica de aliança entre homem e natureza, mas com todo potencial de fazer as transformações no âmbito do meio ambiente, das relações sociais e da própria subjetividade. $\mathrm{Na}$ busca de fazer compreender o sentido de um novo modo de produção social de subjetividade colocada a partir da problemática do pensamento ecopolítico de Ernst Bloch (1959) e Deleuze e Guattari (1972) que compõem em suas constelações conceituais um permanente comprometimento ético-político em relação ao homemnatureza-sociedade num dado pensamento denominado por Félix-Guattari de pensamento ecosófico.

\section{NATUREZA E UTOPIA EM ERNST BLOCH}

\subsection{O sentido da técnica da aliança}

A natureza da técnica como enlace social é fundamento para uma utopia concreta, pois é nestas condições que o homem realiza sua existência, modificando a si mesmo e o meio ambiente. Para Ernst Bloch a técnica da aliança é resposta a problemática da relação homem-natureza de modo a superar o domínio da técnica sobre a natureza por uma expressão de unidade disjuntiva de heterogeneidade, cooprodutividade orgânica e inorgânica, tendo a natureza como amiga e a técnica como libertadora numa aliança homem-natureza.

A utopia concreta vinculada ao processo existe nos dois elementos fundamentais da realidade compreendida em termos marxistas: em sua tendência, como tensão do que 
está na vez mas é tolhido; em sua latência, como elemento correlato das possibilidades reais e objetivas ainda não realizadas no mundo. [...] O mundo todo é um querer intencionar do que ainda não chegou: a utopia concreta é a mais importante teoria e prática dessa tendência (BLOCH, 2006, p.117).

A técnica da aliança também se faz política em seu conteúdo ativo de esperança, no sentido do verbo esperançar, mobilizando objetivamente a práxis social no horizonte concreto da vida, propondo uma crítica ao dado como estabelecido, e impulsionando uma nova relação com a natureza, com o meio social e, com os modos de produção de subjetividade. É preciso ter claro que Bloch faz uma leitura política do constructo conceitual de utopia, retirando as injunções ideológicas e reducionistas para quebrar o velho paradigma que obstaculiza a compreensão de uma utopia concreta, e restitui ao conceito todo o potencial de transformação política. Uma utopia concreta se define através de uma técnica concreta que transforma o mundo, mas não deixa de projetar-se por um mundo ainda melhor. Trata-se de uma produção com base sistêmica entre liberdade social e existência harmônica com as leis da natureza.

A liberdade sociopolítica, que toma nas mãos as causas sociais, prolonga-se, portanto, na política da natureza. Afinal, essa mediação constitui a contraparte técnica e filosófico-natural daquilo que, no relacionamento entre os seres humanos, Engels chamou de salto do reino da necessidade para o da liberdade (BLOCH, 2006, p.251).

Segundo Schütz (2021, p.551-552) o conteúdo utópico não está constituído como "pura fantasia, castelos no ar, ou seja, ilusão e ingenuidade", mas enraizado na história e referenciado socialmente como modelo empírico de uma realidade concreta e ativa da natureza. No campo político a utopia é o movente não binário das forças sociais que compõem passagens de sonhos a esperança concreta por uma determinada transformação. Esta por sua vez, não para de sofrer modificações, seja pelo caráter instrumental e iminentemente prático, ou pelas condições próprias da sociabilidade.

Ao nos compreendermos como participantes do devir do próprio mundo, torna-se possível aproximar utopia e realidade, livrando-a do caráter ilusório que, por vezes, lhe é equivocadamente atribuído. Nesse contexto, Bloch (2005, p. 203ss.) também faz a distinção entre utopia abstrata e utopia concreta. As utopias, para serem concretas, deveriam se edificar a partir das possibilidades naturais e históricas. Sugere, ainda, que sejam transpassadas simultaneamente por duas correntes de pensamento: a corrente quente, correspondente ao entusiasmo militante e à capacidade criativa e fantasiosa; e a corrente fria, que garantiria a identificação e 
análise minuciosas de elementos utópicos da realidade. Utopia e ciência poderiam, assim, se tornar conceitos complementares. O exercício dessa hermenêutica da esperança seria um dos maiores desafios do pensamento emancipatório crítico (SCHÜTZ, 2021, p. 553).

A utopia torna-se um conceito crítico na releitura de Ernst Bloch e tem como foco evidenciar o conteúdo utópico concreto, opondo-se a ideia de utopia como uma espécie de ilusão inatingível, passando a considerar o conteúdo utópico como imagens sociais desejantes, e como tal, um movimento contínuo de luta de forças enraizada na práxis humana. Ernst Bloch é um pensador extremamente ocupado em desenvolver uma discussão existencial a respeito do futuro, mas também de constituir no tempo presente um caminho para práxis vital, de modo a recolocar a questão da utopia em sua expressão mais proeminente, que é da utopia concreta, realizável no campo da subjetividade como condição essencial as transformações sociais.

Embora, o caráter utópico seja constituído como um vetor de criação que potencializa em nós, a capacidade de transpor limites, ou seja, de impulsionar o "ainda-não", exatamente como um devir que requer um espaço concreto na história e na sociedade, também é necessário considerar que o mesmo poder ser instrumentalizado, invertendo-se o conteúdo utópico-social por um paradoxo de utopia da classe dominante. Tal como no exemplo de Bloch, em O Princípio Esperança retratando o sonho $^{2}$ de Platão que vislumbrava uma república aristocrática. Compreende-se neste caso, que o conteúdo utópico se torna um fenômeno amplamente instrumental, contudo, impõe-se a necessidade de estabelecer um critério válido a constituição de uma utopia social, uma vez que esta corre o permanente risco de ser instrumentalizada.

Para Schütz (2021, p.3.), o critério que valida essa formulação de uma utopia social em Bloch é a máxima formulada por Karl Marx (2005, p. 151) no sentido de um “imperativo categórico de derrubar todas as condições em que o homem surge como um ser humilhado, escravizado, abandonado, desprezível” rumo a um "reino da liberdade". (Marx, apud Bloch 2005, p. 131). Trata-se, portanto de uma construção de mundo que busca superar os diversos problemas de ordem sociais, mas também de ordem cosmológica de aliança homem/natureza, de modo a proporcionar uma "naturalização do homem e a humanização da natureza” (Marx, apud Bloch 2005, p. 131). Seguindo esse critério, fica evidente a estreita ligação entre utopia concreta e a técnica da aliança no que diz respeito a esperança de um mundo tecnologicamente desenvolvido e com justiça social para todos no âmbito de uma

\footnotetext{
${ }^{2}$ A República de Platão

Revista Gestão e Sustentabilidade Ambiental., v. 11, n. esp, p. 18-31, jan. 2022.
} 
ecologia social, ambiental e da própria produção de subjetividade, assim, como pensando por FélixGuattari.

Ernst Bloch desenvolve um amplo trabalho histórico sobre o conceito de utopia, perpassando o período clássico, medieval, moderno e contemporâneo da história da filosofia, considerando o direito natural clássico, o direito natural iluminista, o centralismo no século XIX, as utopias individuais e anárquica, além da própria revolução científica e industrial para afirmar conceitualmente a existência de uma utopia concreta produzida historicamente com objetivo de ultrapassar as contradições resultantes do domínio da técnica sobre a natureza, sobretudo após a ascensão da técnica burguesa na sociedade capitalista. O conceito de utopia concreta é herdeira do pensamento materialista e por consequência busca novas relações de produção entre homem, natureza e sociedade, tendo em seu horizonte a ideia de igualdade e justiça social, mas também compreendido como campo criativo das utopias tecnológicas, religiosas, ecológicos e de tantas outras utopias que somente pode vir-a-ser por meio do princípio esperança.

Um aspecto importante a ser considerado é o de não relativizar o conteúdo utópico, mesmo aqueles que estão vinculados a uma tradição mítica-religiosa. Basta lançar um olhar sobre a história que poderemos identificar a natureza de um conteúdo utópico em sua potência de construir realidades e práticas capazes de perdurarem longos anos e manter-se, após de grandes quedas de reinos e impérios. Um exemplo clássico é a utopia na tradição judaico-cristã fortemente nutrida pela esperança de um reino de paz e de amor que não se consolida obviamente neste mundo, mas que torna necessário no tempo presente lançar as sementes do novo reino, ou seja, de realizar uma antecipação dos bens vindouros para que seja possível uma aliança de justiça e de paz, no aqui e no agora. Santo Agostinho em "Cidade de Deus", soube explorar o verbo esperançar como prática imanente, tal como descrita na oração do pai-nosso, "assim na terra como no céu", e na sequência como apresenta, o pão nosso de cada dia, o que identifica a dupla dimensão da esperança, a de tencionar por mudanças, o desejar da cidade dos homens por uma utopia concreta de inspiração na cidade de Deus, passando a contraponto o modelo da sociedade medieval para o advento da renascença.

Um segundo exemplo de conteúdo utópico trazido por Bloch é o de Thomas Morus no sentido de uma utopia como liberdade social, apresentada em sua obra, "A Utopia” de (1516), situado no âmbito da reforma protestante de Henrique VIII, seu pensamento imprime o caráter político do desejo, em contraposição as práticas cerceadoras e autoritárias frente a liberdade religiosa, econômica, e do exercício do poder. Por outro lado, Campanella em "A Cidade do Sol” (escrita em 1602 e publicada 
em 1623), defende uma utopia da ordem social, submetendo ao ordenamento do soberano os senhores feudais, centralizando o poder econômico na figura do Estado, além de exercer o controle social pelo domínio da religiosidade impactando diretamente no exercício dos direitos de propriedade e ou até mesmo sobre a própria liberdade de seus súditos. São posições como essas que precisam de atenção em virtude do potencial político e de seus impactos sociais que eles são capazes de causar. Para Bloch nem mesmo a ciência escapa de um conteúdo utópico, assim como no exemplo de Francis Bacon em a "Nova Atlântida" de (1627) que postula uma utopia da técnica no sentido de que seria possível a dominação da natureza, com objetivo de afastar o sofrimento da humanidade.

Sua tese utópica afasta-se do discurso mítico, esperançada pelo sonho científico, e desenvolve no âmbito social a tese de uma utopia do melhor Estado, sendo este, portanto capaz de remover as injustiças e desigualdades da sociedade de sua época. No entanto, a história da ciência nos mostra que o caminho da técnica realizou uma mudança de direção, ajustando-se ao modelo de uma técnica burguesa de produção e exploração social, mas a esperança precisa do verbo esperançar para que seja possível tencionar o melhor mundo possível e não nos conformamos com o que está posto no âmbito das três ecologias.

Também é importante compreender a crítica ao pensamento utópico, que ganhou força ao considerar apenas o aspecto abstrato de seu conteúdo, formulando assim, a hipótese da impossibilidade de uma utopia concreta. Tendo, pois, a ausência de correspectivo empírico como fator decisivo para tal conclusão. No entanto, a materialidade dessas transformações ocorrem em condições internas que tenciona o corpo social a projetar-se na construção do "ainda-não", sem a qual não seria possível produzir qualquer ação revolucionária, portanto, o pensamento utópico não é menos concreto ou menos realizável pela ausência de um correspectivo empírico, mas revolucionário na medida em que produz o novo e modifica o já estabelecido, isto é, mediação da natureza com a vontade humana, toda uma técnica da aliança e de agenciamentos maquínicos que compõem a utopiasocial.

Essas linhas utópico-concretas decorrem, na técnica, de forma singularmente clara da incumbência de uma relação concreta entre sujeito e objeto. De modo que o sujeito seja mediado com o objeto natural, o objeto natural com o sujeito, e que entre si os dois não mais se comportem como estranhos. Uma perda de organicidade que abandona completamente o orgânico e finalmente o mesocósmico não deve perder a conexão com o sujeito humano, que justamente na tecnologia, segundo a bela expressão de Engels, visa transformar as coisas em si em coisas para nós (BLOCH, 2006, p.219-220). 
A técnica da aliança equivale a uma teoria geral a respeito de uma coprodutividade de um possível sujeito da natureza, como definido por Bloch (2006, p,227), "um sujeito dinâmico na natureza constitui em última instância, um sinônimo para o impulso inicial ainda não manifesto como princípio ativo material mais imanente no real propriamente dito". Vale dizer que não se trata de um animismo, mas da capacidade real da natura naturans ${ }^{3}$ em gerar a própria natureza como a ideia de uma matéria criadora, anterior à natura naturada 4 que em cooperação constitutiva compõe uma tecnologia da vontade e de aliança concreta com os fenômenos da natureza e suas leis mediadas do sujeito humano.

A natureza não é fato passado, mas o canteiro de obras ainda não desocupado, o material de construção ainda não adequadamente existente destinado a edificar a casa humana ainda não adequadamente existente. A capacidade do sujeito problemático da natureza de cooperar na construção dessa casa constitui o correlativo utópicoobjetivo da fantasia utópico-humanitária, como fantasia concreta. Por essa razão, é certo que a casa humana não apenas está situada na história e sobre o chão da atividade humana, como também se encontra sobretudo sobre o chão de um sujeito mediado da natureza e sobre o canteiro de obras da natureza (BLOCH, 2006, p.224225).

A técnica da aliança é um contraponto a técnica burguesa, ao modelo de produção do capitalismo que se deslocou do sujeito da natureza por uma alienação, perdendo a organicidade e a conexão com a natureza e com o próprio homem. Segundo Bloch (2005, p.246) "O mundo burguês das máquinas se encontra entre o que foi perdido e o que ainda não foi conquistado". A crise da técnica burguesa não encontra-se na criação de novas tecnologias, mas na não-mediação com a substância de suas produções, alienação do conteúdo da natureza em razão da exploração abstrato- capitalista, tendo o domínio da técnica sobre a natureza, mas não propriamente o sujeito da natureza que por conseguinte carece de sua produção e instala-se a pulsão abstrata pelo lucro como crise própria do capital em absoluto.

Assim como lá onde a história ainda não é compreendida como sendo trabalho comum rumo a uma sociedade solidária tornam-se dominantes relações de produção que oprimem e exploram os seres humanos trabalhadores e, com isso, atravancam o caminho do progresso do processo histórico, assim também lá onde nós não mais ou ainda não compreendemos a natureza enquanto processo em devir, a natureza é tratada como um material que pode ser manipulado e explorado arbitrariamente. Mas

\footnotetext{
${ }^{3}$ Conceito de Baruch Spinoza que refere-se a constituição de uma natureza imanente e autoprodutora.

${ }^{4}$ Conceito Spinozano que designa a natureza como resultado da força imanente e autoprodutora.

Revista Gestão e Sustentabilidade Ambiental., v. 11, n. esp, p. 18-31, jan. 2022.

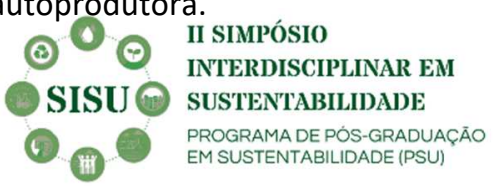


essa crescente alienação dos seres humanos em relação à sua base natural viva na qual eles mesmos estão inseridos, por fim, volta-se contra eles mesmos: a história humana não pode se afirmar contra os processos naturais que a tudo envolvem, mas somente, na medida das possibilidades da práxis humana, realizar-se em aliança com a natureza; o fim último da história e do processo natural é, pois - como formula Bloch em continuidade com o Jovem Marx -,a naturalização do homem e humanização da natureza (SCHÜTZ, 2019, p.14-15).

A partir dessa posição crítica frente ao desenvolvimento capitalístico, torna-se necessário recolocar a razão histórico-mundial, enquanto produção social de uma tarefa de responsabilidade frente a natureza, que não é somente compreendida como um processo de devir, mas como materialidade da qual se pode manipular de maneira arbitrária, e que por isso, necessita de uma práxis humana consciente com objetivo de construir "um mundo onde possamos sentir-nos acolhidos, como se estivéssemos a viver em paz em nosso lar (Heimat), pois nos sentiríamos verdadeiramente em casa conosco, com nossos semelhantes e com a natureza"(SCHÜTZ, 2021, p. 553), de modo a intervir produtivamente num horizonte de esperança, a partir de uma técnica de aliança com a natureza, como técnica da liberação criadora dos potenciais de uma utopia concreta.

\section{3 . NATUREZA E SUBJETIVIDADE MAQUÍNICA EM DELEUZE E GUATTARI}

\subsection{Por uma aliança de heterogeneidade maquínica}

Assim como Ernst Bloch considerou necessária uma técnica da aliança para tratar da relação homem/natureza, com objetivo de estabelecer a práxis de responsabilidade sobre a vida no planeta, também será necessário considerar o pensamento ecosófico de Félix-Guattari como uma resposta ao problema dessa relação, mas sob uma espécie de articulação ético-político no âmbito dos três registros ecológicos, o do meio ambiente, o das relações sociais e o da subjetividade humana. Essa articulação de instâncias tão heterogêneas permite compreender que "já não há nem homem nem natureza, mas unicamente um processo que os produz um no outro e, acopla as máquinas" (DELEUZE E GUATTARI, 2010, p.12). Neste sentido, homem e a natureza é uma só e mesma realidade compreendida como processo de produção por uma aliança maquínica.

Há menos ainda a distinção homem-natureza: a essência humana da natureza e a essência natural do homem se identificam na natureza como produção ou indústria, isto é, na vida genérica do homem, igualmente. Assim, a indústria não é mais considerada numa relação extrínseca de utilidade, mas em sua identidade 
fundamental com a natureza como produção do homem e pelo homem. Não homem como rei da criação, mas antes como aquele que é tocado pela vida profunda de todas as formas ou de todos os gêneros, que é encarregado das estrelas e até dos animais, que não para de ligar a máquina órgão a uma máquina energia, uma árvore no seu corpo, um seio na boca, o sol no $\mathrm{Cu}$ : o eterno encarregado das máquinas do universo (DELEUZE E GUATTARI, 2010, p.15).

O conceito de máquina proposto por Deleuze e Guattari, considera os fenômenos biológicos, sociais, econômicos não apenas no aspecto de relações autorreguladoras de estruturas sistêmicas, mas as que desenvolve em relação a exterioridade como um diálogo de alteridade em seu ambiente tecnológico e humano, por isso, o conceito de máquina se estende para a constituição de máquinas urbanas, máquinas linguísticas, máquinas abstratas e máquinas desejantes.

Isso funciona em toda parte: às vezes sem parar, outras vezes descontinuamente. Isso respira, isso aquece, isso come, Isso caga, isso fode. Mas que erro ter dito o isso. Há tão somente máquinas em toda a parte, e sem qualquer metáfora: máquinas de máquinas com seus acoplamentos, suas conexões. Uma máquina-órgão é conectada a uma máquina fonte: esta emite um fluxo que a outra corta. O seio é uma máquina que produz leite, e a boca, uma máquina que acopla a ela (DELEUZE E GUATTARI, 2010, p.11).

O conceito de máquina não implica somente um devir constituinte de formas de humanidade, mas também devires animais, vegetais, musicais integrando entidades não discursivas, máquinas abstratas, os incorporais e outros diferentes estratos sociais e ecológicos, que requer uma produção criadora no campo da ciência, da filosofia, das artes e no campo da produção social de subjetividade. A ecosofia consiste em uma produção de sistemas múltiplos de valorização da heterogeneidade, caracterizado por uma concepção transversalista, pensada como processo de produção e de agenciamento de subjetivação.

Uma ecosofia de um tipo novo, ao mesmo tempo prática e especulativa, éticopolítica e estética, deve a meu ser substituir as antigas formas de engajamento religioso, político, associativo. Ela não será nem uma disciplina de recolhimento na interioridade, nem uma simples renovação das antigas formas de "militantismo". Tratar-se-á antes de um movimento de múltiplas faces dando lugar a instâncias e dispositivos ao mesmo tempo analítico e produtores de subjetividade. Subjetividade tanto individual quanto coletiva, transbordando por todos os lados a circunscrições, e abrindo-se em todas as direções: do lado do socius, mas também dos philum maquínico, dos Universos de referência técnico-científico, dos mundos estéticos, e ainda do lado das novas apreensões "pré-pessoais" do tempo, do corpo, do sexo. Subjetividade de ressingularização capaz de receber cara-a-cara o encontro com a finitude sob a forma do desejo, da dor da morte (GUATTARI,1990, p.54-55). 
Trata-se de uma práxis que leva em consideração um paradigma ético-estético de criação de relações com o mundo, com o outro e, não somente com alteridade humana, mas com os diferentes modos de expressão da natureza. Assim, ao tratar de uma subjetividade ecosófica, Félix-Guattari desenvolve uma espécie de desnaturalização da subjetividade, passando a considerar o sujeito como um domínio do fora, resultado de uma anti-produção como sujeição social, do qual precisa emanciparse para constituir a subjetividade maquínica de produção desejante.

O indivíduo não é objeto último da programação de um tipo de equipamento. Com efeito, se é verdade que se encontrou no final da cadeia de todos os equipamentos, como produto terminal, bem como no início da cadeia, como base, é igualmente verdade que as coisas não param por aí. A imagem dessa circularidade corre até o risco, a nosso ver, de fechar com pouca rapidez, e a preço muito bom, os processos de alienação do capitalismo sobre entidades localizáveis, apelando para denúncias de bom senso do tipo: É necessário reequilibrar as relações entre homem e a cidade, entre o homem e a máquina, etc. E para manter o mito de uma essência humana que, em todos os casos, escaparia às tecnologias de modelagem de indivíduos. O indivíduo é uma sociedade inteiramente fabricada, particularmente por seus equipamentos coletivos. (GUATTARI, 2013, p.30-31).

A noção de agenciamentos coletivos de enunciação, apresenta-se como contraponto a ideia de sujeito irredutível aos processos de subjetivação capitalista, sujeito livre, autônomo e consciente, que na verdade serve de suporte ideológico com objetivo de aniquilar qualquer projeto coletivo. A subjetividade coletiva são componentes parciais e heterogêneos de agenciamentos coletivos de enunciação, como multiplicidades de relações humanas e não humanas, como os devires animais, vegetais, maquínicos e de valores incorporais sob a égide de uma ecosofia.

A discursividade maquínica sempre tem seu correlato em um agenciamento de enunciados não discursivos, com ruptura para o significante. Não faço a máquina depender da techné, considero que a techné é apenas um caso de maquinismo, amplio o conceito de máquina, não sou o único no sentido que falavam Francisco Varela e Humberto Maturana uma máquina sistêmica, Chomsky de uma linguística. Penso que existe um nível maquínico que atravessa, que se corporifica em níveis tecnológicos, biológicos, artísticos, estéticos, etc. O que conta, na máquina, não são suas engrenagens, mas, como diz Varela, sua organização autopoiética. Varela diferencia as máquinas alopoiéticas que produzem algo diferente delas mesmas, das máquinas autopoiéticas, que engendram sua própria organização. Considero as máquinas alopoiéticas estão sempre em relação às máquinas autopoiéticas e constituem agenciamentos com seres humanos. Eles são autopoiéticos por delegação. (GUATTARI, 2015, p.129). 
Segundo Félix-Guattari a ecosofia não consiste em uma teoria acabada, mas em um modo teórico-prático que envolve processos contínuos, referentes ao meio ambiente em seus domínios materiais e energéticos, mas também as questões sociais e de produção de subjetividade, integrado por agenciamentos maquínicos de heterogeneidade. A ecosofia é um modo de pensar o presente e o futuro, mas não como um modo de ideologizar o verde como uma ecologia centrada na natureza, como uma visão identitária que pode converter-se em um conservadorismo autoritário, mas por uma ecologia que defenda as espécies materiais, vegetais, animais de maneira inseparável das questões que envolvem as espécies incorporais, os valores, os universos de sentidos e os territórios existenciais.

Não haverá verdadeira resposta à crise ecológica a não ser em escala planetária e com a condição de que se opere uma autêntica revolução política, social e cultural reorientando os objetivos da produção de bens materiais e imateriais. Esta revolução deverá concernir, portanto, não só em relações de forças visíveis em grandes escalas mas também aos domínios moleculares de sensibilidade, de inteligência e de desejo (GUATTARI,1990, p.9).

A ecosofia é uma prática ético-política que busca uma nova aliança maquínica entre homemnatureza, colocando em chaves transversais o mundo-ambiente e os grandes agenciamentos institucionais, a fim de reposicionar as práticas micropolíticas e microssociais referente ao modo de produção e consumo da sociedade capitalista ao qual encontra-se submetidos os modos de produção social de subjetividade. Embora, o conceito de técnica da aliança seja composto por elementos de constelações distintas, uma aproximação com o conceito de agenciamentos maquínicos de aliança entre homem-natureza é possível, visto que ambos compreendem uma crítica aos modos de produção capitalista e, consequentemente de sua composição social de subjetividade. Ambos propõem uma mudança revolucionária, de um lado a revolução de uma utopia concreta, a qual reconstrói o mundo tomando conhecimento da natureza e, a partir dela, age conjuntamente intervindo, não de maneira mecanicista, mas em interconexão produzindo a vida em termos de uma potência de aliança entre homem-natureza. De outro uma revolução molecular, objetivando transformar os modos de produção social de subjetividade em seus diferentes níveis, criando uma nova perspectiva em relação a sociedade, ao meio ambiente e a própria constituição de singularidade diante dos desafios do mundo contemporâneo.

\section{CONSIDERAÇÕES FINAIS}

Revista Gestão e Sustentabilidade Ambiental., v. 11, n. esp, p. 18-31, jan. 2022. 
A aproximação dessas duas perspectivas teóricas, nos parece não só complementar por traçarem um limiar entre homem, natureza e técnica, mas por sua condição inovadora pois indica desde pontos de vista teóricos bastante diversos um fim ético e político comum por uma utopia imanente, libertária e revolucionária, sem jamais remeter as ameaças de restauração transcendente, totalitárias, religiosas e estatais, mas de um movimento de forças do real em agenciamentos coletivos de enunciação e pela técnica da aliança para liberar a imanência de todos os limites impostos pelo capitalismo, seja no âmbito social, ambiental e da produção de subjetividade. A utopia imanente é correspectivo de uma utopia concreta do real que embora não sendo atual é por sua vez real-virtual capaz de abolir a condição em que se encontra movendo-se na direção do não idêntico da própria diferença.

\section{REFERÊNCIAS}

BLOCH, Ernst. O princípio esperança, vol. II. Tradução de Nélio Schneider. Rio de Janeiro: EdUERJ: Contraponto, 2006.

DELEUZE, G.; GUATTARI, F. O Anti-Édipo: capitalismo e esquizofrenia 1. Tradução de Luiz. B. Orlandi. São Paulo: Editora 34, 2010.

GUATTARI, Félix. As Três Ecologias. Tradução de Maria Cristina F. Bittencourt. Campinas: Papirus, 1990.

. Caosmose: Um novo paradigma estético. Tradução de Ana Lúcia de Oliveira e Lúcia Claúdia Leão, São Paulo: Ed 34.2006.

Cactus,2013. .Líneas de fuga: por outro mundo de posibles. Tradução de Pablo Ires. Buenos Aires:

Qué es la Ecosofía? Textos presentados y agenciados por Stéphane Nadaud. Tradução de Pablo Ires. Buenos Aires: Cactus, 2015.

SCHÜTZ, R."Ernst Bloch: Esperança por uma aliança entre história e natureza”. In: Revista Veritas, vol.64.Porto Alegre,2019. http://revistaseletronicas.pucrs.br/ojs/index.php/veritas/article/view/34619/19202/ (Acesso em:20 jul.2021).

SCHÜTZ, R. Verbete Utopia de Ernst Bloch. In: SIVERES, L.; NODARI, P.C. (Orgs.). Dicionário de Cultura de Paz. Vol.2. Curitiba: Editora CRV, 2021. 